We investigated the serum macrophage migration inhibitory factor (MIF) levels of palmoplantar pustulosis patients, before and after the tonsillar provocation test. Higher serum MIF levels of palmoplantar pustulosis patients were decreased after the tonsillar provocation test $(n=29)$. To confirm these phenomena, two patients with acute tonsillitis had their changes in body temperature, C-reactive protein (CRP) and serum MIF levels examined during the course of their illness. Surprisingly, increased MIF preceded fever and CRP elevation, and MIF subsequently decreased at the onset of fever and CRP elevation. Since MIF is an initiator of other proinflammatory cytokines, we suggest that the induction of MIF may precede other inflammatory conditions.

Key words: Migration inhibitory factor, Focal infection, Tumor necrosis factor alpha, Tonsillitis

\section{Induction of macrophage migration inhibitory factor precedes the onset of acute tonsillitis}

\author{
Tadamichi Shimizu ${ }^{1, C A}$, Hironori Niizeki ${ }^{2 *}$, \\ Osamu Takeuchi ${ }^{3}$, Yuichiro Yamasaki ${ }^{2}$, \\ Nobuko Inamoto ${ }^{4}$, Yukihiro Kusunoki ${ }^{5}$, \\ Kunihiko Kobayashi ${ }^{6}$, Riichiro Abe ${ }^{1}$, \\ Hiroshi Shimizu', Takeji Nishikawa", \\ Kazuhiro Hashiguchi ${ }^{8}$ and Jun Nishihira ${ }^{9}$
} ${ }^{1}$ Department of Dermatology, ${ }^{6}$ Department of
Pediatrics and ${ }^{9}$ Department of Molecular
Biochemistry, Hokkaido University Graduate School
of Medicine, Sapporo, Japan; ${ }^{2}$ Department of
Dermatology and Clinical Research Institute, National
Tokyo Medical Center, Tokyo, Japan; ${ }^{3}$ Division of
Basic Research, Kitasato Institute Hospital, Tokyo,
Japan; ${ }^{4}$ Department of Dermatology and ${ }^{5}$ Department
of Otolaryngology, Kitasato Institute Hospital, Tokyo,
Japan; ${ }^{7}$ Department of Dermatology, Keio University
School of Medicine, Tokyo, Japan and ${ }^{8}$ Department of
Pediatrics, Teine Keijinkai Hospital, Sapporo, Japan
CACorresponding Author
Tel: +81117161161 , ext. 5962
Fax: +81117067820
E-mail: michiki@med.hokudai.ac.jp
Macrophage migration inhibitory factor (MIF) is an important cytokine in the innate immune system and plays an important role in the control of such inflammatory responses. ${ }^{1}$ Once released, MIF induces the expression of proinflammatory mediators by macrophages and activates $T$ cells, thereby promoting inflammatory and immune responses. ${ }^{2}$ Elevated concentrations of MIF have been detected in sera from patients with a variety of inflammatory disorders such as atopic dermatitis. ${ }^{3}$

We investigated serum levels of MIF in patients with palmoplantar pustulosis (PPP) and compared them before and after the tonsillar provocation test (TPT) in each patient. PPP is a common chronic skin disease characterized by recurrent sterile pustules and usually also by erythematous, scaly skin on the palms and soles. It has been reported that PPP is

* Present address: Department of Dermatology, Nara Medical University, 840 Shijocho, Kashihara, Nara 634-8522, Japan. closely related to focal tonsil infections, and that tonsillectomy is often effective in curing this condition. ${ }^{4}$ The TPT is a well-established laboratory procedure to evaluate whether the tonsils participate in the etiology of inflammatory skin diseases such as PPP and psoriasis. ${ }^{4}$ Twenty-nine patients with PPP (10 males and 19 females; aged 19-78 years, mean age $46.3 \pm 1.3$ years) and 135 healthy volunteers ( 47 males and 88 females; aged $22-73$ years, mean age $47.6 \pm 0.82$ years) were enrolled in the present study. None of the patients had been treated with systemic immunosuppressants before the TPT. Controls did not have any acute or chronic illness at the time of the study. All participants gave informed consent. The TPT was performed by indirect ultramicrowave irradiation (Micro thermy ME-320; OG Giken, Okayama, Japan) as described previously. ${ }^{4}$ Blood samples were collected before and $1 \mathrm{~h}$ after TPT. Serum MIF was measured by enzyme-linked immu- 
nosorbent assay (ELISA) as previously described. ${ }^{3}$ Briefly, the anti-human MIF antibody dissolved in 50 $\mu \mathrm{l}$ of phosphate-buffered saline was added to each well of a 96-well microtiter plate. After incubation for $1 \mathrm{~h}$ at room temperature, the plate was washed and $50 \mu \mathrm{l}$ of biotin-conjugated anti-human MIF antibody was added. Following incubation, the plate was again washed. Then avidin-conjugated horseradish peroxidase was added to individual wells, which were further incubated for $1 \mathrm{~h}$ at room temperature. After washing again, $50 \mu \mathrm{l}$ of substrate solution containing $200 \mu \mathrm{g}$ of $\mathrm{o}$-phenylenediamine and $10 \mathrm{ml}$ of $30 \%$ hydrogen peroxide in $10 \mathrm{ml}$ of citrate-phosphate buffer ( $\mathrm{pH}$ 5.0) were added. Then the reaction was terminated with $50 \mu \mathrm{l}$ of $1 \mathrm{~N}$ sulfuric acid. The absorbance at $492 \mathrm{~nm}$ was measured with an ELISA plate reader (Model 3550; Bio-Rad, Tokyo, Japan). For this assay we used recombinant human MIF to obtain the standard curve, in which good linearity was demonstrated between MIF concentrations (1$200 \mathrm{ng} / \mathrm{ml}$ ) and absorbency. C-reactive protein (CRP) was measured using a Hitachi modular system 7350 (normal range, $0-0.39 \mathrm{mg} / \mathrm{dl}$ ).

Table 1 summarizes the data. The mean serum MIF level before the TPT in the PPP patients was $11.32 \pm$ $2.0 \mathrm{ng} / \mathrm{ml}(n=29)$, which was significantly higher than that of control subjects $(4.78 \pm 0.32 \mathrm{ng} / \mathrm{ml}$, $n=135 ; p=0.0027)$. In contrast, the mean serum MIF level in the PPP patients was significantly decreased after the TPT $(8.3 \pm 1.1 \mathrm{ng} / \mathrm{ml}$ )(before TPT versus after TPT, $p=0.016$ ). Elevation of CRP was detected after the TPT in each patient (data not shown).

To confirm these phenomena, two patients with acute tonsillitis had their changes in body temperature, CRP and serum MIF levels examined during the course of their illness. Six-year-old and 9-year-old male patients were admitted to Hokkaido University hospital with acute tonsillitis. In both cases, increased serum MIF levels preceded both fever and CRP
Table 1. Serum MIF contents of PPP patients and MIF contents fell after the TPT

\begin{tabular}{lcc}
\hline Patients & $\begin{array}{c}\text { Number of } \\
\text { patients }\end{array}$ & $\begin{array}{c}\text { Serum MIF } \\
(\mathrm{ng} / \mathrm{ml})^{\mathrm{a}}\end{array}$ \\
\hline Control & 135 & $4.78 \pm 0.32$ \\
PPP patients before the TPT & 29 & $11.32 \pm 2.0^{*}$ \\
PPP patients after the TPT & 29 & $8.3 \pm 1.1^{* *}$ \\
\hline
\end{tabular}

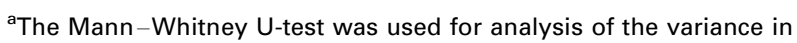
serum MIF levels contents between several of the two groups. ${ }^{*}$ Control versus patients before the TPT, $p=0.0027, * *$ PPP patients before the TPT versus after the TPT, $p=0.016$.

elevation, MIF levels were also reduced at the onset of fever and elevation of CRP (Fig. 1).

In vitro cytokine measurements of tonsil mononuclear cells stimulated with $\alpha$-streptococcal antigens revealed significant tumor necrosis factor alpha (TNF$\alpha$ ) production in the culture supernatants from PPP patients but not controls. ${ }^{4}$ These findings suggested a close immunologic link between the tonsillitis and proinflammatory cytokines. It has been shown that the TPT induces an increased level of some inflammatory cytokines such as TNF- $\alpha$, interleukin- 1 and interleukin-6 in peripheral blood monocytes of patients with certain focal infectious skin diseases. We have observed two cases with acute tonsillitis, which showed a transient increase in serum MIF preceding an elevation of CRP and fever. In addition, MIF levels were decreased at the onset of fever and the elevation of CRP. Furthermore, significantly higher MIF contents were observed in the sera of patients with PPP than in normal subjects. Unexpectedly, the MIF serum level fell after the TPT. The fact that the serum MIF level significantly decreased at the onset of fever and elevation of CRP after the TPT seems to be a surprising, but interesting, result.

Monocytes and macrophages are the main sources of MIF, which is released after exposure to bacterial endotoxins and exotoxins such as lipopolysaccharide and streptococcal pyrogenic exotoxin A. ${ }^{2}$ Thus, these effects may be mediated by a number of proinflam-
Case 1

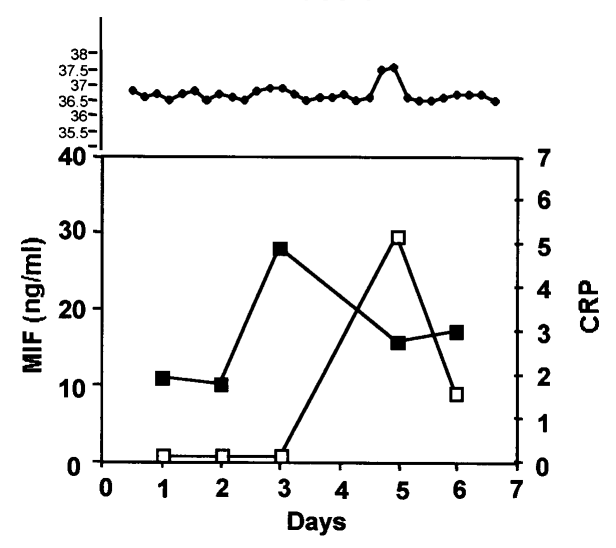

Case 2

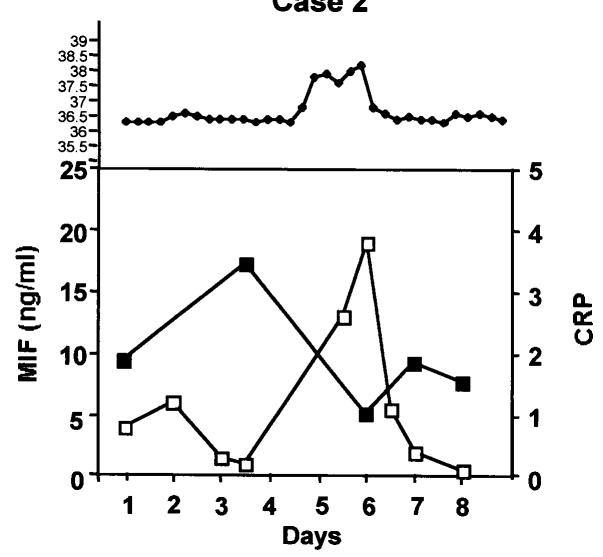

FIG. 1. Changes in body temperature, serum MIF, and CRP in patients with acute tonsillitis. The patients with acute tonsillitis (case 1, a 6-year-old male; and case 2, a 9-year-old male) were admitted to Hokkaido University hospital. Body temperature, CRP ( $\square)$, and serum MIF ( $\square$ ) were examined during the course of admission. 
matory cytokines, including TNF- $\alpha$ and IL- $1 .{ }^{2}$ Since MIF is an initiator of other proinflammatory cytokines such as TNF- $\alpha$ and IL-1, and regulates the induction of those cytokines, ${ }^{1,5}$ our findings suggest that the induction of MIF may precede that of other inflammatory conditions.

ACKNOWLEDGEMENTS. This work was supported by Grants-in-Aid for Scientific Research from the Ministry of Education, Science, and Culture of Japan (numbers 11670813, 13357008, 12671692, and 14571650).

\section{References}

1. Nishihira J. Macrophage migration inhibitory factor (MIF): its essential role in the immune system and cell growth. I Interferon Cytokine Res 2000; 20: $751-762$.
2. Calandra T, Bernhagen J, Mitchell RA, Bucala R. The macrophage is an important and previously unrecognized source of macrophage migration inhibitory factor. J Exp Med 1994; 179: 1895-1902.

3. Shimizu T, Abe R, Ohkawara A, Nishihira J. Increased production of macrophage migration inhibitory factor by PBMCs of atopic dermatitis. J Allergy Clin Immunol 1999; 104: 659-664.

4. Murakata H, Harabuchi Y, Kataura A. Increased interleukin-6, interferongamma and tumour necrosis factor-alpha production by tonsillar mononuclear cells stimulated with alpha-streptococci in patients with pustulosis palmaris et plantaris. Acta Otolaryngol 1999; 119: 384-391.

5. Metz CH, Bucala R. MIF. In Oppenheim JJ, Feldmann M, eds. Cytokine Reference. New York: Academic Press, 2000:704-716. 


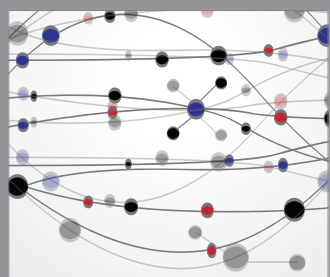

The Scientific World Journal
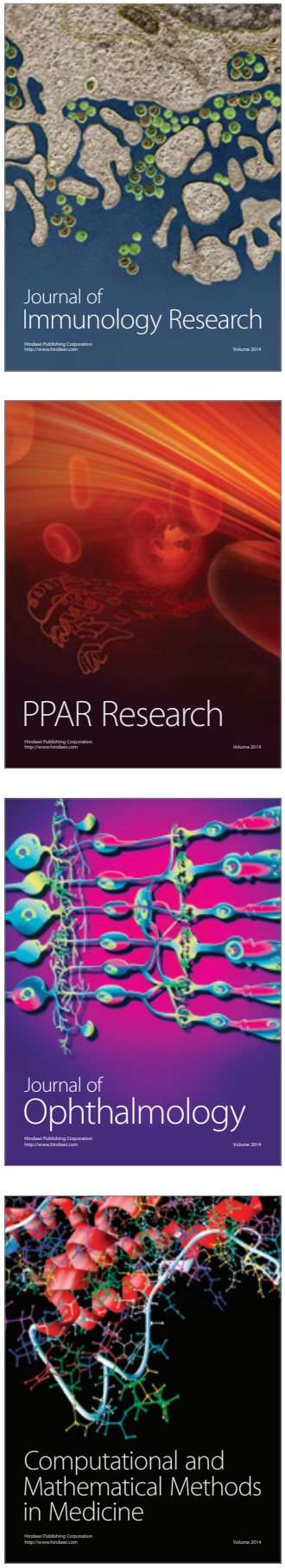

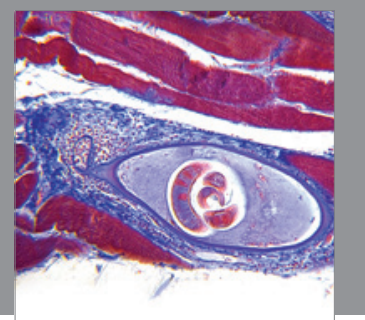

Gastroenterology

Research and Practice
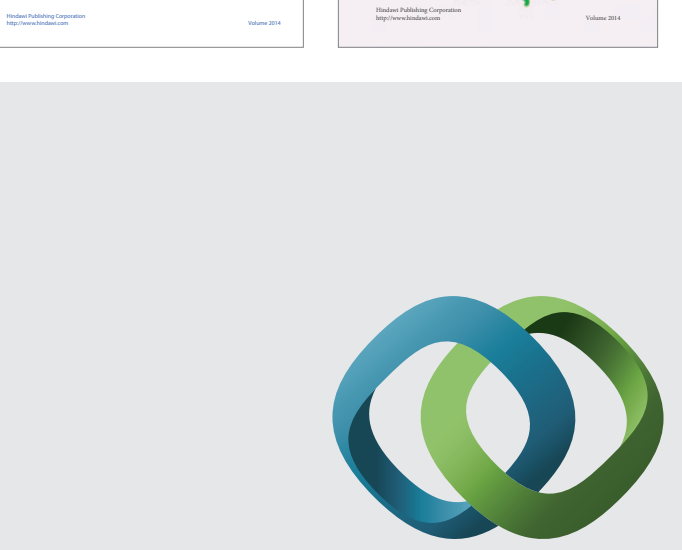

\section{Hindawi}

Submit your manuscripts at

http://www.hindawi.com
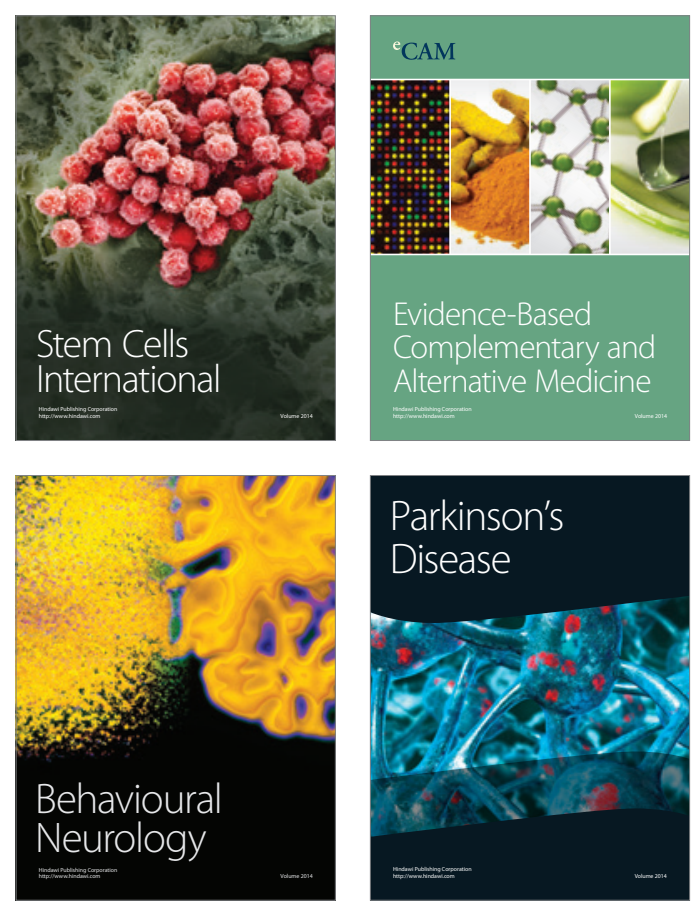

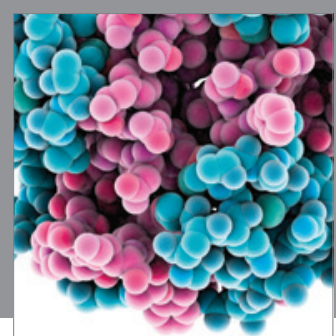

Journal of
Diabetes Research

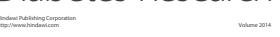

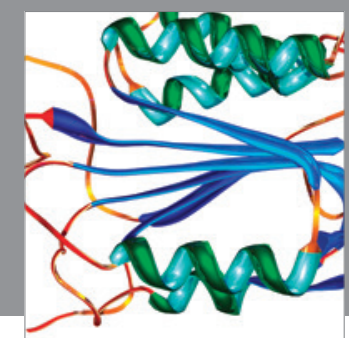

Disease Markers
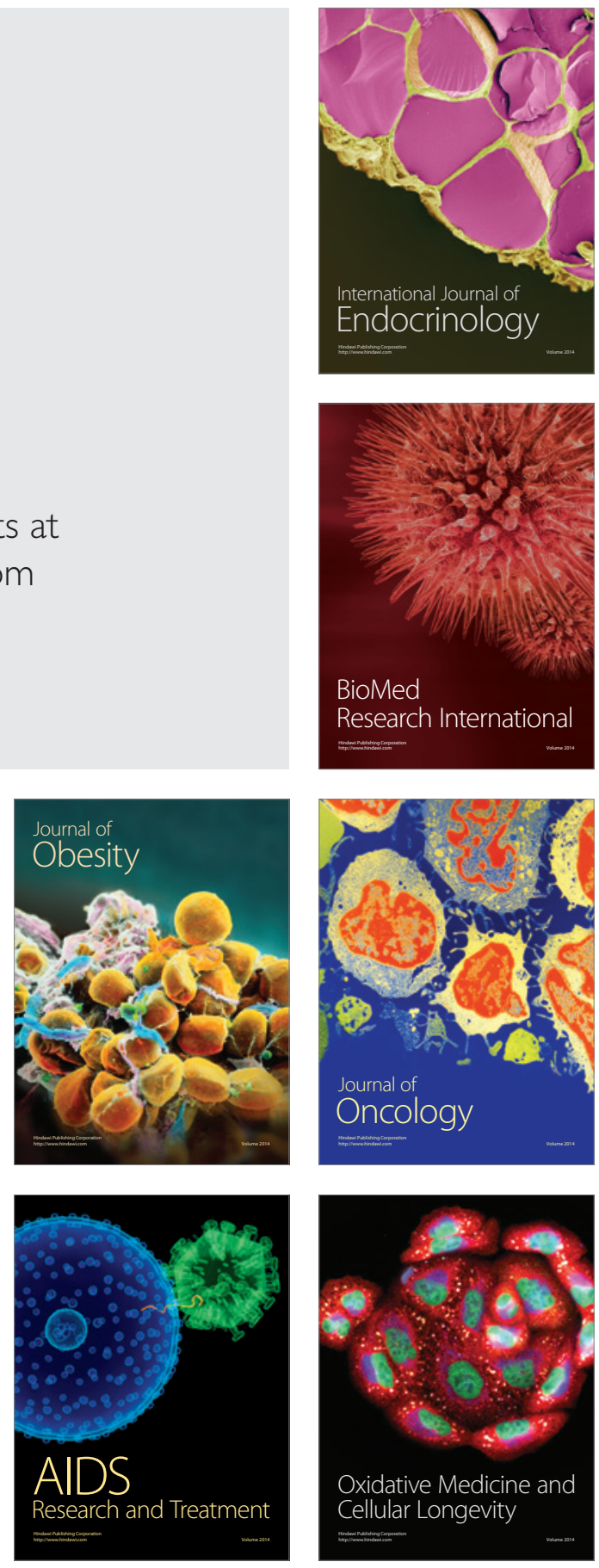